\title{
Craniofacial adaptation to protrusive function in young rhesus monkeys
}

\author{
Jose Carlos Elgoyhen, D.D.S.,* Robert E. Moyers, D.D.S., Ph.D., \\ James A. McNamara, Jr., D.D.S., Ph.D., and \\ Michael L. Riolo, D.D.S., M.S. \\ Ann Arbor, Mich.
}

\begin{abstract}
$\mathrm{I}_{\mathrm{t}}$
is still not fully understood how clinical corrections are achieved by activators and other related orthodontic and orthopedic procedures, largely because the role of function in craniofacial growth and orthodontic treatment is not yet clear. Numerous experiments have been conducted using different methods and producing widely varying results. Clinical studies have offered one avenue of approach to this problem. Patients trcatcd by one of the functional jaw orthopedic methods have been analyzed individually or compared to untreated controls. Many of these studies reported differences in the craniofacial growth pattern, particularly in the mandible. ${ }^{1-4}$ Both Browne ${ }^{1}$ and Marschner and Harris, ${ }^{2}$ in two of the few clinical studies that consider total mandibular length rather than mandibular positioning, noted significantly higher mandibular growth rates in the treated groups. However, Björk ${ }^{5}$ stated that any skeletal changes during this type of treatment may well be within the range of normal growth. Other investigators ${ }^{5-7}$ found that treatment had no apparent effect on mandibular growth but, rather, acted by reshaping the alveolar arches, by altering vertical dimension, and by affecting the eruption and alignment of teeth. Definitive comparisons among these findings are somewhat obscured by differences in measuring methods, experimental design, and treatment procedures.

Experimental approaches have also been taken. The studies most relevant to the clinician have been those utilizing nonhuman primates. Since the original

\footnotetext{
From the Center for Human Growth and Development and Department of Analomy, The University of Michigan.

This study was supported in part by United States Public Health Service Grants DE-02272 and DE-43120.

*Present address: Buenos Aires, Argentina.
} 


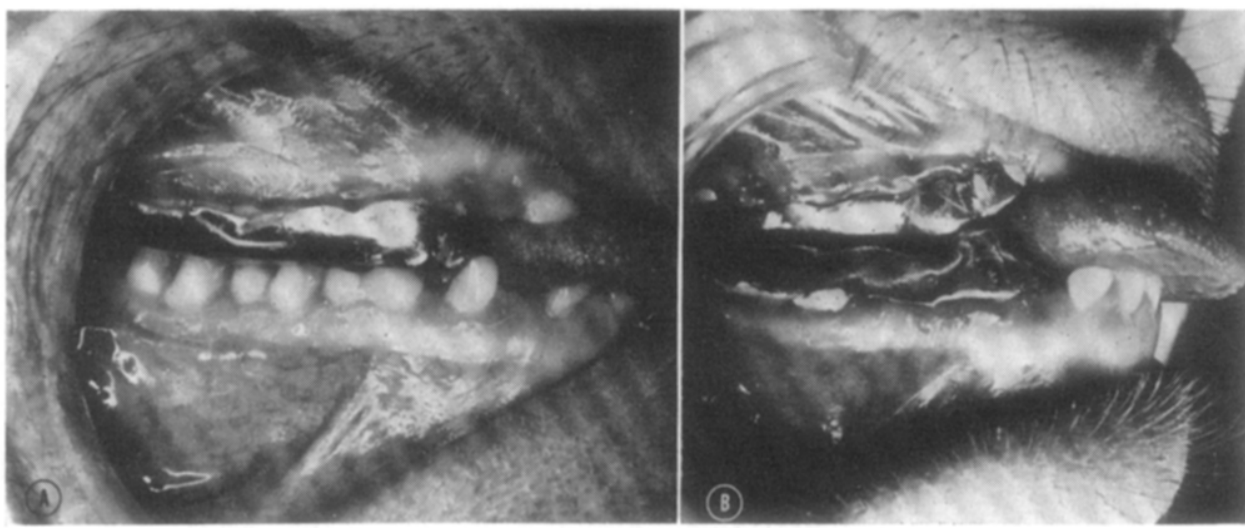

Fig. 1. The two basic types of appliance. A, Unimaxillary; B, bimaxillary.

work of Breitner, ${ }^{8}$ a series of experiments involving anterior displacement of the lower jaw has shown various alterations in mandibular morphology. Some investigators ${ }^{9-12}$ attributed the observed changes to adaptation in the temporomandibular joint, while others stated that these changes were limited to the gonial angle and/or alveolar structures. ${ }^{13,14}$ In most primate studies of facial growth, the experimental group has been quite small and the control sample limited or absent. For example, Breitner ${ }^{8}$ examined two experimental animals and observed that craniofacial adaptation was due in part to a mesial migration of the glenoid fossa, although Zimmermann ${ }^{15}$ has since shown that such a histologic picture can be observed in normal remodeling of the temporal articulation. For more certain interpretation of results, it seems important to provide an adequate control group to which experimental findings can be compared and to provide quantification of results, since descriptive techniques have proverl inadequate. This article reports a series of experiments using young rhesus monkeys (Macaca mulatta) in which the effects of functional mandibular displacement were assessed. A new occlusal configuration has been devised which prompts anterior positioning of the mandible during functional movements. Through serial cephalometric radiography with metallic implants, both skeletal and dental adaptations have been studied and compared to a control group.

\section{Materials and methods}

Sixteen juvenile rhesus monkeys (Macaca mulatta) were studied, six in experimentation and ten as controls. These animals were selected on the basis of their dental development, the criteria being the full eruption of the upper and lower first permanent molars and the presence of all deciduous incisors, canines, and molars. According to current tables of tooth eruption, ${ }^{16}$ this corresponds to a chronologic age of approximately 20 to 24 months. This age was selected because it is equivalent to the human developmental age of 6 to 8 years, a period in which growth potential exists and during which much functional jaw orthopedic treatment has been successfully attempted.

Tantalum pins were inserted in the maxillas and mandibles of all animals 
according to a method previously described. ${ }^{17}$ The monkeys were also injected with tetracycline hydrochloride on two occasions for microfluorescent analysis. Reports of this and other histologic studies will be presented in other reports.

Upper and lower impressions were taken of each animal in the experimental group, and from these impressions duplicate casts obtained-one for reference and the other one for construction of the appliances. The appliances were gold castings which served to prompt all occlusal function a specified distance forward. Vertical displacement was minimized, providing only enough opening to allow for construction of the appliance. Two types of appliance were designed (Fig. 1). A unimaxillary appliance, used on three monkeys, covered all upper teeth from the mesial aspect of the deciduous canines to the distal aspect of the first permanent molars (Fig. $1, A$ ). Each unimaxillary appliance had a carefully contrived occlusal configuration which simulated the maxillary occlusal anatomy. A bimaxillary type of appliance was designed for the other three monkeys. All buccal segments were covered and connected by two transverse palatal bars in the upper arch and a lingual connecting bar in the lower arch. The posterior occlusal surfaces of these appliances were designed flat, while the gold surfaces mesial to the canines formed an incline (Fig. 1,B), thus prompting the mandible forward during closure and function. The unimaxillary appliances were designed to provide forward mandibular displacement of 2,4 , and $5 \mathrm{~mm}$. The bimaxillary appliances provided 2, 4, and $6 \mathrm{~mm}$. of displacement. Before cementation, the buccal and lingual surfaces of the involved teeth were grooved superficially to increase retention.

The three monkeys with bimaxillary appliances were observed and radiographed for several months before placement of the appliances. This control period enabled us to compare growth changes in each animal before and after cementation of the appliance. Cephalometric roentgenograms were taken monthly with a cephalostat specifically designed for primate research. ${ }^{17}$ Two exposures were made each time, one in occlusion and one with the mouth open to allow for better definition of the condylar structures. Two aspects of the radiographic technique proved to be significant in our study. First, the use of industrial film allowed for fine definition of structures. Second, each radiograph was enlarged three times on translite film, providing the opportunity to trace and measure changes in growth increments which normally would be masked by tracing error.

Error of the melhod determination. In order to measure any bias involved in analysis, six series of cephalograms involving three experimental and three control monkeys were retraced and measured by a second observer. This procedure was followed for the three condylar measurements (Fig. 2) on a total of twenty-four x-ray films. The mean differences between double determinations and standard errors were computed and statistically tested. No significant differences between the measurements of the two observers were noted.

In order to test the accuracy of the method, at least one set of duplicate cephalograms was obtained for each animal by removing the animal from the cephalostat after exposure and repositioning him. A total of twenty-eight pairs of cephalograms were obtained, traced, and superimposed on the mandibular 


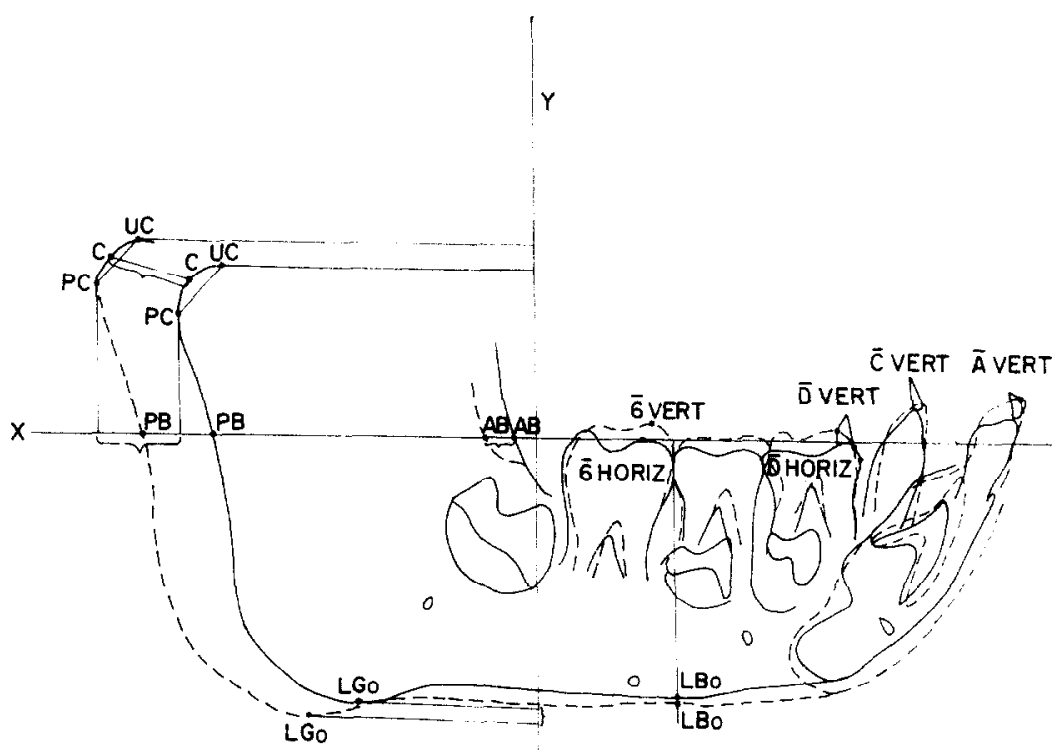

Fig. 2. Points and lines used in measuring mandibular dimensions. UC, Uppermost portion of the condyle outline determined by a tangent perpendicular to Y. PC, Most posterior point of the condyle outline determined by the tangent perpendicular to $\mathbf{X}$. $\mathbf{C}$, Condylion, the most posterior and superior point on the condyle, determined by the intersection with the condylar outline of a perpendicular traced to the midline of the line joining PC and UC. PB, Intersection of the extended occlusal plane line with the posterior border of the ramus. AB, Intersection of this same line with the anterior border of the ramus. LGo, Lowermost point on the gonial region determined by a tangent perpendicular to $Y$. LBo, Intersection of a perpendicular to the occlusal plane through the contact $\bar{\sigma}$ and with the lower border of the mandible. $\overline{6}$ Horizontal, Mesial point of the bisected outline of $\overline{6 \mid 6}$. $\overline{6}$ Vertical, Uppermost point of the mesial buccal cusp of $\overline{6} / \overline{6}$. $\bar{D}$ Horizontal, Mesial point of the bisected outline of $\bar{D} \mid \bar{D}$. $\bar{D}$ Vertical, Uppermost point of the mesial cusp of $\bar{D} \mid \bar{D}$. $\overline{\mathbf{C}}$ Horizontal, Mesial point of the bisected outline of $\bar{C} \mid \bar{C} . \bar{C}$ Vertical, Uppermost point of the bisected cusp of $\bar{C} \mid \bar{C}$. $\bar{A}$ Horizontal, Most mesial point of the labial surface of $\bar{A} \mid \bar{A}$. $\bar{A}$ Vertical, Incisal portion of $\bar{A} \mid \bar{A}$.

implants, and the differences for each condylar measurement were computed. The values of the accidental errors, expressed as the standard error for a single measurement, ranged from \pm 0.20 to $\pm 0.28 \mathrm{~mm}$.

\section{Findings}

All of the animals seemed to adapt quickly to the appliances and the subsequently induced changes in function. There was no observable alteration in feeding habits or measurable loss of weight. After a period of approximately 3 to 4 months, there was evident mandibular prognathism, although the condyle seemed fully and normally articulated. In no instance could the mandible bc forced into its original relationship, even when this was attempted with the 

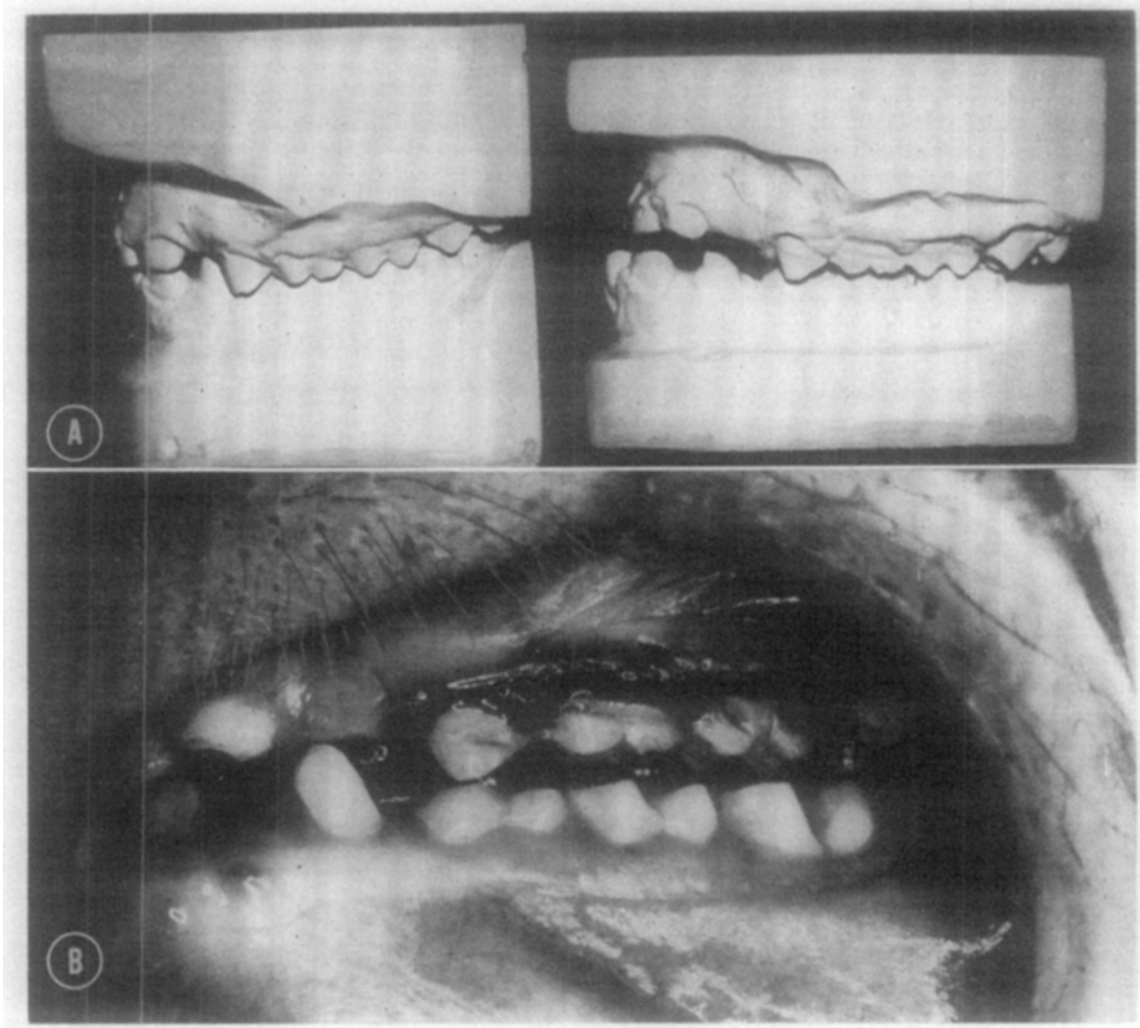

Fig. 3. A, Casts before and after use of the appliance for a 5-month period. Note the anteroposterior changes and the altered occlusal relations impeding full occlusion. B, Intraoral view immediately after removal of the appliance.

animal under general anesthesia. After removal of the appliances at 5 months, all of the animals had developed a Class III molar relationship. A posterior open-bite also was observed, the occlusion being maintained by contact in the incisal region and/or by the cusp tip of the upper canine contacting the lower first deciduous molar. The maxillary first permanent molar appeared almost without an ocelusal antagonist since the mandibular second molars were still unerupted (Fig. 3). The ten control animals had Class I molar relationships, and none developed a spontaneous ocelusal alteration during the study. Little variability in molar relationship has been noted in Macaca mulatta. ${ }^{17}$

Analysis of the serial cephalograms demonstrated that, after the original functional alteration of the condyle-fossa relationship, the condyle tended gradually to grow into its original anatomic position relative to the glenoid fossa and other temporal structures. In an attempt to ascertain the relative contributions of one or more possible factors leading to the observed change, 3-month and 5-month changes were compared between the experimental and the control groups and mean monthly increments were computed for both groups.

Mandible. Serial mandibular tracings were superimposed on the implants. 
Table I. Comparison of summated increments after the third month between the experimental and control groups

\begin{tabular}{|c|c|c|c|c|c|c|c|c|}
\hline \multirow[b]{2}{*}{ Variables } & \multicolumn{3}{|c|}{ Experimental $(n=6)$} & \multicolumn{3}{|c|}{ Control $(n=10)$} & \multirow[b]{2}{*}{$t$} & \multirow[b]{2}{*}{$P$} \\
\hline & $\begin{array}{c}\bar{X}_{1} \\
\left(m m_{.}\right)\end{array}$ & $\begin{array}{c}S D_{i} \\
(m m .)\end{array}$ & $\begin{array}{l}\text { Range } \\
(m m .)\end{array}$ & $\begin{array}{c}\bar{X}_{z} \\
(m m .)\end{array}$ & $\begin{array}{c}S D_{z} \\
(m m .)\end{array}$ & $\begin{array}{l}\text { Range } \\
\text { (mm.) }\end{array}$ & & \\
\hline \multicolumn{9}{|l|}{ Mandible } \\
\hline P. C. & 3.0 & 0.44 & 2.4 to 3.5 & 1.9 & 0.80 & 0.5 to 3.4 & 3.178 & 0.01 \\
\hline U. C. & 2.1 & 0.94 & 0.9 to 3.2 & 1.3 & 0.63 & 0.2 to 2.5 & 2.140 & 0.05 \\
\hline C. & 3.5 & 0.48 & 3.0 to 4.2 & 2.1 & 0.64 & 1.1 to 2.8 & 4.472 & 0.001 \\
\hline P. B. & 2.6 & 0.44 & 2.0 to 3.2 & 1.9 & 0.61 & 1.1 to 3.2 & 2.094 & 0.10 \\
\hline
\end{tabular}

Measurements for all tables have been derived from the enlarged films and subsequently reduced by a factor of 3 to represent actual values. Student's $t$ values were computed he. foro reduction. In all tables $P$ represents the level of significance.

Table II. Comparison of summated increments after 5 months between the experimental and control groups

\begin{tabular}{|c|c|c|c|c|c|c|c|c|}
\hline \multirow[b]{2}{*}{ Variables } & \multicolumn{3}{|c|}{ Experimental $(n=6)$} & \multicolumn{3}{|c|}{ Control $(n=10)$} & \multirow[b]{2}{*}{$t$} & \multirow[b]{2}{*}{$P$} \\
\hline & $\begin{array}{c}\bar{X}_{1} \\
(m m .)\end{array}$ & $\begin{array}{c}S D_{1} \\
(m m .)\end{array}$ & $\begin{array}{l}\text { Range } \\
\text { (mm.) }\end{array}$ & $\begin{array}{c}\bar{X}_{2} \\
(m m .)\end{array}$ & $\begin{array}{c}S D_{2} \\
\left(m m_{.}\right)\end{array}$ & $\begin{array}{l}\text { Range } \\
(m m .)\end{array}$ & & \\
\hline \multicolumn{9}{|l|}{ Mandible } \\
\hline P. C. & 4.4 & 0.61 & 3.6 to 5.1 & 3.3 & 1.02 & 2.1 to 5.0 & 2.261 & 0.05 \\
\hline U.C. & 3.6 & 1.00 & 2.0 to 4.7 & 2.3 & 0.65 & 1.4 to 4.1 & 2.222 & 0.05 \\
\hline C. & 5.5 & 0.61 & 3.7 to 6.4 & 4.0 & 0.81 & 3.1 to 5.5 & 3.655 & 0.005 \\
\hline P. B. & 4.0 & 0.54 & 3.6 to 4.8 & 3.3 & 0.84 & 1.6 to 4.1 & 1.902 & 0.10 \\
\hline$\overline{6}$ Horizontal & 0.8 & 0.34 & 0.5 to 1.4 & 0.3 & 0.32 & 0 to 0.9 & 3.202 & 0.01 \\
\hline$\underline{6}$ Vertical & 0.7 & 0.52 & 0.5 to 1.5 & 1.0 & 0.40 & 0.5 to 1.6 & 1.672 & 0.20 \\
\hline$\underline{\bar{D}}$ Horizontal & 0.7 & 0.30 & 0.4 to 1.1 & 0.2 & 0.32 & 0 to 0.8 & 2.957 & 0.025 \\
\hline$\overline{\mathrm{C}}$ Horizontal & 0.9 & 0.60 & 0.3 to 1.9 & 0.2 & 0.24 & -0.5 to 0.5 & 3.292 & 0.01 \\
\hline $\overrightarrow{\mathrm{C}}$ Vertical & 0.5 & 0.21 & 0.3 to 0.8 & 0.7 & 0.46 & 0.1 to 1.4 & 0.931 & 0.50 \\
\hline$\overline{\mathrm{A}}$ Horizontal & 0.6 & 0.42 & 0 to 1.2 & 0.2 & 0.35 & -0.3 to 0.7 & 1.746 & 0.20 \\
\hline A Vertical & 1.2 & 0.48 & 0.6 to 1.8 & 0.7 & 0.42 & 0.2 to 1.4 & 1.909 & 0.10 \\
\hline \multicolumn{9}{|l|}{ Maxilla } \\
\hline 'T'uberosity & 2.0 & 0.43 & 1.3 to 2.3 & 1.4 & 0.64 & 0.5 to 2.1 & 1.887 & 0.10 \\
\hline 6 Horizontal & 0.4 & 0.47 & 0 to 1.2 & 1.1 & 0.35 & 0.7 to 1.6 & 3.103 & 0.01 \\
\hline$\overline{6}$ Vertieal & 0.5 & 0.40 & 0 to 1.0 & $0 . \overline{7}$ & 0.34 & 0.4 to $1 . t$ & 1.037 & 0.50 \\
\hline$\underline{\bar{D}}$ Horizontal & 0.4 & 0.24 & 0.1 to 0.8 & 1.0 & 0.36 & 0.5 to 1.8 & 3.834 & 0.005 \\
\hline I) Vertical & 0.4 & 0.24 & 0.1 to 0.8 & 1.0 & 0.29 & 0 to 1.7 & 3.848 & 0.005 \\
\hline U Iorizontal & 0.5 & 0.27 & 0.2 to 0.9 & 1.0 & 0.28 & 0.6 to 1.4 & 3.431 & 0.005 \\
\hline S Vertical & 0.3 & 0.36 & 0 to 0.8 & 0.5 & 0.49 & 0 to 1.3 & 0.915 & 0.50 \\
\hline$\underline{\text { A Vertical }}$ & 0.6 & 0.39 & 0 to 1.0 & 0.4 & 0.36 & 0 to 1.2 & 1.117 & 0.50 \\
\hline
\end{tabular}

On the initial tracing of each animal, a line $X$ was traced through the natural plane intersected by a perpendicular $Y$, thus creating a system of coordinates (Fig. 2). This template provided a means of quantifying skeletal and dental changes relative to these lines in successive tracings.

After 3 months the only significant differences observed between the experi- 

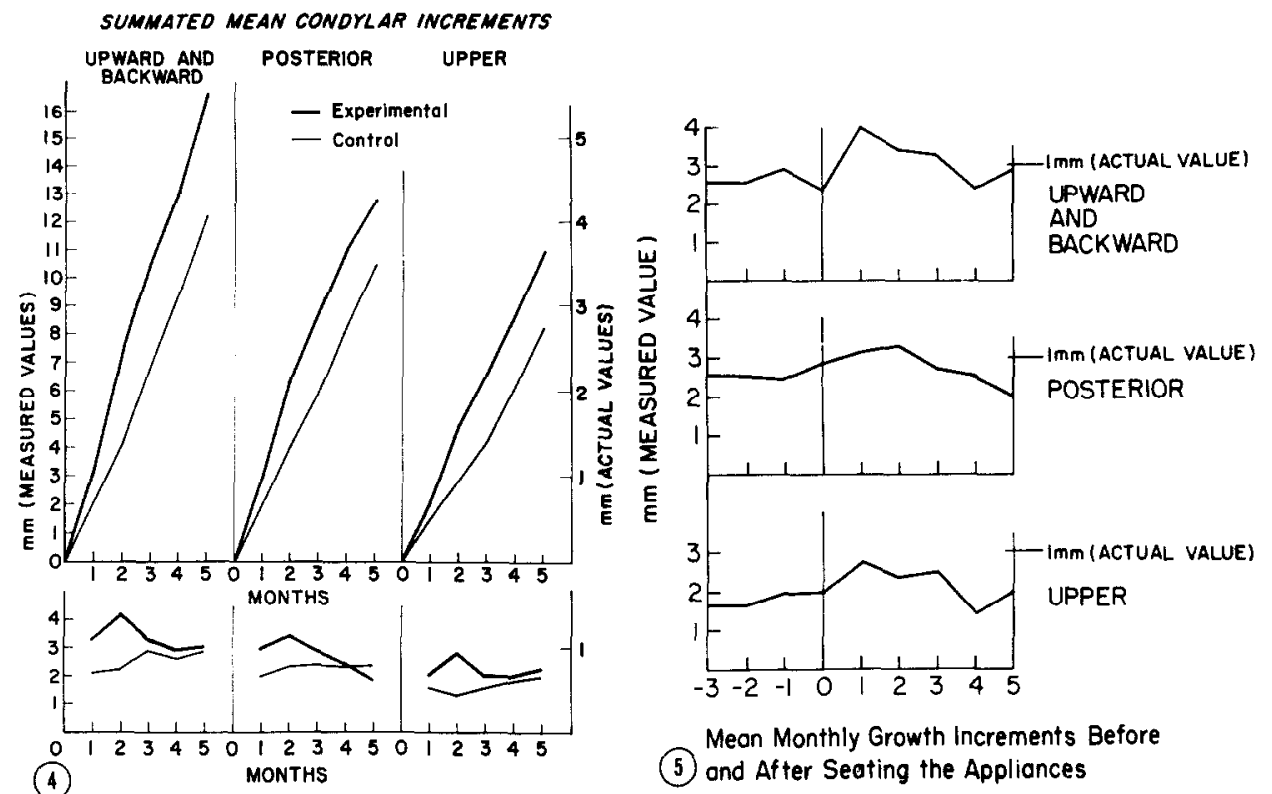

Fig. 4. Above, Summated monthly increments compared between experimental and control animals. Below, Mean monthly increments compared between experimental and control animals.

Fig. 5. Mean monthly increments 3 months before and 5 months after appliance cementation on three monkeys.

mental and control animals were found in the three condylar measurements. The experimental animals expressed a 58 to 66 per cent average incremental increase relative to the control group in the condylar area, the difference between each set of measurements being at least at the 0.05 level of significance (Table I). There was also a trend toward increased growth at the posterior border of the mandible. No significant differences in any other skeletal or any of the mandibular dental measurements were noted at the end of 3 months. While the summated condylar increments of the experimental group still were significantly different after 5 months (Table II), the net incremental increase during the last 2 months was similar to that of the control group (Fig. 4). During the latter 2 months a significant migration of the lower buccal segment occurred, a situation not observed in the analysis after 3 months.

Incremental graphies of the mean monthly changes of the three condylar measurements for the experimental and control samples illustrated that the skeletal changes in the experimental group tended to occur during the first 3 months after placement of the appliance (Fig. 4). A peak appeared in the second month, and by the fourth month growth tended to parallel the control group. This trend was also found in a comparison of the condylar increments averaged for each month before and after setting the appliances for three monkeys for which at least 3 months of control records were available (Fig. 5).

Maxilla. Maxillary structures were superimposed on the maxillary implants 

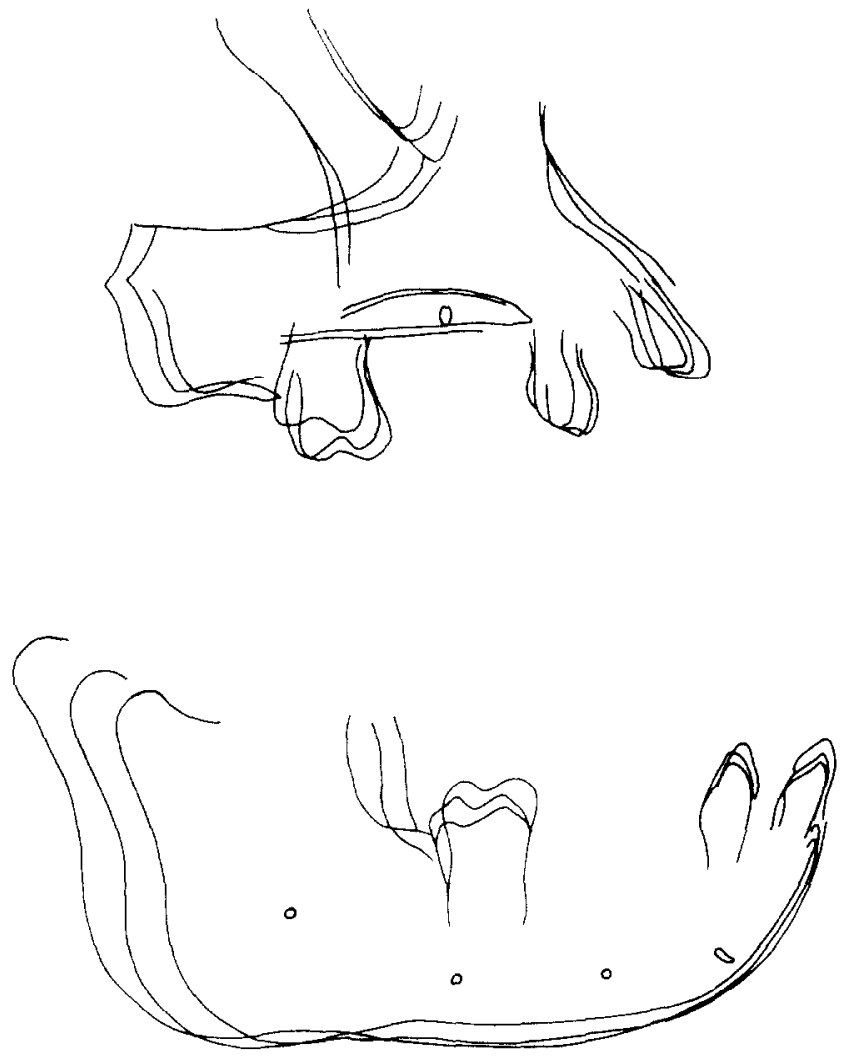

Fig. 6. Tracings of the maxilla and mandible of an animal 5 months before, at cementation, and after 5 months when the appliance was removed. Superimposition is on the implants. Note the relative inhibition of eruption of the maxillary molar and the increased growth increments at the head of the condyle during the experimental phase.

for each series of tracings of each monkey, and the changes within the maxilla were recorded. These changes were measured by tracing a line parallel to the occlusal plane on the initial tracing through one of the palatal implants and a perpendicular to this plane through the most posterior and lowest points in the outline of the tuberosity. Incremental changes relative to these two lines were measured. No significant differences were observed in any of the skeletal or dental measurements after 3 months. However, at the 5-month analysis, an inhibition of the forward migration and of the vertical development of the maxillary buccal segments was noted (Table II). There was also a trend toward increased growth at the tuberosity in the experimental animals.

Maxillomandibular relationships. Changes in mandibular position relative to the maxilla also were computed while the maxilla was superimposed on its implants. Changes in maxillomandibular relationships and changes relative to the cranial base were analyzed only after a 5-month period because the appliances completely altered the vertical dimension while in the mouth, making any type of analysis during this period meaningless. Even after removal of 
Table III. Relative differences in the behavior of the maxillary and mandibular implants with the tracings superimposed on the cranial base

\begin{tabular}{|c|c|c|c|c|c|c|c|c|}
\hline \multirow[b]{2}{*}{ Variables } & \multicolumn{3}{|c|}{ Experimental $(n=6)$} & \multicolumn{3}{|c|}{ Control $(n=10)$} & \multirow[b]{2}{*}{$t$} & \multirow[b]{2}{*}{$P$} \\
\hline & $\begin{array}{c}\bar{X}_{1} \\
(m m .)\end{array}$ & $\begin{array}{c}S D_{t} \\
(m m .)\end{array}$ & $\begin{array}{l}\text { Range } \\
\text { (mm.) }\end{array}$ & $\begin{array}{c}\bar{X}_{2} \\
(m m .)\end{array}$ & $\begin{array}{c}S D_{z} \\
(m m .)\end{array}$ & $\begin{array}{l}\text { Range } \\
\text { (mm.) }\end{array}$ & & \\
\hline \multicolumn{9}{|l|}{ Mandible } \\
\hline \multicolumn{9}{|l|}{ Horizontal: } \\
\hline Ramus implant & 4.2 & 0.59 & 3.2 to 4.9 & 2.9 & 1.30 & 1.2 to 4.3 & 2.114 & 0.10 \\
\hline Body implant & 4.3 & 0.32 & 3.7 to 4.5 & 3.0 & 1.30 & 1.5 to 5.0 & 2.121 & 0.10 \\
\hline Chin implant & 4.3 & 0.16 & 4.2 to 4.5 & 3.1 & 1.23 & 1.7 to 5.0 & 2.218 & 0.05 \\
\hline \multicolumn{9}{|l|}{ Vertical: } \\
\hline Ramus implant & 3.7 & 0.67 & 2.9 to 4.2 & 3.2 & 0.85 & 1.9 to 4.8 & 1.310 & 0.25 \\
\hline Body implant & 3.0 & 0.80 & 2.1 to 4.3 & 2.6 & 0.84 & 1.1 to 4.0 & 0.960 & 0.50 \\
\hline Chin implant & 2.8 & 0.91 & 1.9 to 4.3 & 2.4 & 1.02 & 0.5 to 4.1 & 0.874 & 0.50 \\
\hline \multicolumn{9}{|l|}{ Maxilla } \\
\hline ITorizontal & 2.4 & 0.49 & 1.8 to 3.1 & 1.5 & 0.63 & 0.7 to 2.9 & 2,663 & 0.025 \\
\hline Vertical & 0.8 & 0.89 & 0 to 2.0 & 1.2 & 0.29 & 0 to 1.9 & 1.122 & 0.40 \\
\hline
\end{tabular}

the onlays, changes in height in the lower face were somewhat distorted by cuspal interferences and molar occlusion. After 5 months, a trend toward a more downward and forward position of the mandible in the experimental animals was apparent. The increase in vertical displacement was partially caused by the slight overeruption of the ineisors while the appliance was cemented on the posterior teeth.

Cranial base. Successive tracings of each animal were superimposed on the cranial base by attempting to achieve maximum superimposition on the anterior wall of the outline of sella, the great wings of the sphenoid, and the outline of planum sphenoidale. Using a method similar to that used for the maxilla, an expression of the changes of the mandible relative to the cranial base and possibly a suggestion of the sutural contribution to the growth of the upper face could be attained. The mandible was significantly more prognathic in the experimental group. However, the maxilla also demonstrated a redirected growth pattern. The horizontal/vertical ratio of maxillary growth was $5: 4$ in the control group (Table III). In the experimental group this ratio was altered to $3: 1$, indicating not only an increased forward component of growth but also an inhibition of vertical displacement of the maxilla. Thus, the vector of growth in the maxilla was altered by the appliance. Tracings of cephalograms of an animal 5 months before, at the time of insertion of a bimaxillary appliance, and after removal of the appliance 5 months later typify some of the over-all changes seen in the experimental group (Fig. 6).

\section{Discussion}

The findings reported in this article indicated that a change in the maxillomandibular relationship can be achieved in young monkeys after the animals have been subjected to a forward alteration of the mandibular functional 
position. These results did not appear to be caused by a single anatomic change or factor. Rather, the occlusal alterations were due to an interrelated series of both pronounced and subtle changes in several separate regions within the craniofacial complex. One important factor was the change in condylar growth, where a statistically significant increase in both the rate and the extent of growth was observed. It is interesting to note that this increase occurred only during the first 3 months of the experimental period and that the increments during the last 2 months were equivalent to those observed in the control group. These findings may indicate that functional responses may be time related and that the appliance could have been activated again after 3 months.

A redirection of the vector of growth of the maxilla also was observed. Vertical displacement was inhibited while the entire maxillary complex was displaced anteriorly. Neuromuseular reaction to stretehing of the masticatory muscles may have resulted in an inhibition of vertical growth. This is supported by the observed undereruption of the molars of both arches (Table II). However, it is also possible that the force created by the reflex anterior positioning of the mandible may be directly or indirectly transmitted to the maxillary complex, producing a related adaptive reaction. Other investigators have reported vector changes in maxillary growth. The use of cervical traction direetly to the maxilla by Sproule ${ }^{18}$ produced a downward and backward redirectioning of growth. Joho, ${ }^{19}$ Adams, ${ }^{20}$ and Janzen and Bluher ${ }^{21}$ reported changes in maxillary growth vectors, even when retraction was applied directly to the mandible.

Other adaptations were also observed throughout other skeletal elements, such as the cranial base and sutural systems. Evaluation of these areas and the nature of their interrelationships are currently being studied in detail.

Dentoalveolar changes were seen clearly in our study. Elgoyhen and associates $^{17}$ have demonstrated that the eruptive pattern of the maxillary dentition of Macaca mulatta was normally downward and forward, while the mandibular dentition erupted primarily in a vertical direction. The experimental animals in this study demonstrated an inhibited anterior and vertical cruption pattern in the upper buccal segments, as well as some mesial migration of the lower buccal segments during the later stages of the experimental period. Harvold $^{22}$ has stressed the importance of control of vertical dimension and of differential eruption of teeth during development. He has reported marked occlusal changes in monkeys by experimental alteration of muscle function and mandibular positon. Joho ${ }^{14}$ studied changes in the occlusion of the Macaca irus caused by experimentally induced forward positioning of the mandible. Using a cephalometric approach without implants, Joho noted a strong tendency toward dentoalveolar adaptation as well as structural adaptation in opening of the gonial angle. He was unable to detect changes in total mandibular length, but it should be noted that his measurements did not include the condyle. We thought that the enlargement of the eephalogram facilitated the detection of changes which normally would be masked by tracing errors in conventional procedures. 


\section{Summary and conclusions}

The maxillomandibular relationship in six young male rhesus monkeys was functionally altered anteriorly through the use of gold onlays of two specific designs. Ten animals were used as controls. At the end of 3 months all experimental animals exhibited mandibular prognathism. After the appliances were removed at the end of 5 months, all six monkeys demonstrated a skeletal Class III molar relationship.

This change in maxillomandibular relationship seemed to be due to both pronounced and subtle alterations throughout the craniofacial complex. Statistically significant increases in rate and amount of growth at the head of the condyle were measured. The growth vector of the maxilla was altered to a more forward direction with an inhibition of vertical development. Dentoalveolar adaptation was evidenced by significant inhibition of the normal eruption pattern of the maxillary dentition and limited mesial migration of the lower buccal segments. These changes, in combination with less obvious adaptations in other areas of the craniofacial complex, led to the observed jaw relationships.

The authors wish to acknowledge the help and advice of Dr. Lee W. Graber on this project. Editorial assistance was provided by Mrs. Ruth Bigio. Illustrations were prepared by Miss Sally Everhardus.

\section{REFERENCES}

1. Browne, R. W.: A cephalometric study of effective mandibular length ehanges seen in patients treated with functional jaw orthopedic appliances, M.S. thesis, The University of Michigan, Ann Arbor, 1959.

2. Marschner, J. F., and Harris, J. E.: Mandibular growth and Class II treatment, Angle Orthod. 36: 89-93, 1966.

3. Meach, C. L.: A cephalometric comparison of bony profile changes in Class II, Division 1 patients treated with extraoral force and functional jaw orthopedics, AM. J. ORTHOD. 52: 353-370, 1966.

4. Freunthaller, P.: Cephalometric observations in Class II, Division 1 malocclusions treated with the activator, Angle Orthod. 37: 18-25, 1967.

5. Björk, A.: The principle of the Andresen method of orthodontic treatment; a discussion based on cephalometric x-ray analysis of treated eases, AM. J. ORTHOD. 37: 437-458, 1951.

6. Jakobsson, S. O.: Cephalometric evaluation of treatment effect on Class II, Division 1 malocclusions, AM. J. ORTHOD. 53: 446-457, 1967.

7. Harvold, E. P., and Vargervik, K.: Morphogenic response to activator treatment, AM. J. ORTHOD. 60: 478-490, 1971.

8. Breitner, C.: Experimentelle Veränderung der mesiodistalen Beziehungen der oferen und unteren Zahnreihen, Z, Stomatol. 28: 343-356, 1930.

9. Häupl, K., and Psansky, R.: Experimentelle Untersuchungen über Gelenktransformation bei Verwendung der Methoden der Funktionskieferorthopädie, Dtsche Zahn-, Mund-, Kieferheilkd, 6: 439-448, 1939.

10. Derichsweiler, H.: Experimentelle Tieruntersuchungen über Veränderungen des Kiefergelenkes bei Bisslageveränderung, Fortschr. Kieferorthop. 19: 30-44, 1958.

11. Baume, L. J., and Derichsweiler, H.: Is the condylar growth center responsive to orthodontic therapy An experimental study in Macaca mulatta, Oral Surg. 14: 347-362, 1961.

12. Stöckli, P. W., and Willert, H. G.: Tissue reactions in the temporomandibular joint resulting from anterior displacement of the mandible in the monkey, AM. J. ORTHOD. 60: 142-155, 1971. 
13. Hiniker, J. J., and Ramfjord, S. P.: Anterior displacement of the mandible in adult rhesns monkeys, J. Prosthet. Dent. 16: 503-512, 1966.

14. Joho, J.-P.: Changes in form and size of the mandible in the orthopaedically treated Macaca irus (an experimental study), Trans. Europ. Orthod, Soc. 44: 161-173, 1968.

15. Zimmermann, H. I.: The normal growth and remodeling of the temporomandibular joint of Macaca mulatta, M.S. thesis, University of Washington, Seattle, 1971.

16. Hurme, V. O., and Van Wagenen, G.: Basic data on the emergence of permanent tecth in the rhesus monkey (Macaca mulatta), Proc. Am. Philo. Soc. 105: 105-116, 1961.

17. Elgoyhen, J. C., Riolo, M. I., Graber, L. W., Moyers, R. L., and McNamara, J. A., Jr.: Craniofacial growth in juvenile Macaca mulatta: A cephalometric study, Am. J. Phys. Anthropol. 36: 369-376, 1972.

18. Sproule, W. R.: Dentofacial changes produced by extraoral cervical traction to the maxilla of the Macaca mulatta; a histologic and serial cephalometric study, M.S. thesis, University of Washington, Scattle, 1968.

19. Joho, J.-P.: The effects of extraoral low pull traction to the mandibular dentition of Macaca mulatta, M.S. thesis, University of Washington, Seattle, 1971.

20. Adams, C. D.: The effects of continuous posterior mandibular furces (Class III) on the temporomandibular joint and the dentofacial skeleton of the Macaca mulatta, M.S. thesis, University of Washington, Seattle, 1969.

2.1. Janzen, E. K., and Bluher, J. A.: The cephalometric, anatomic and histologic changes in Macaca mulatta after application of a continuous-acting retraction force on the mandible, AM. J. ORTHOD. 51: 823-855, 1965.

22. Harvold, E. P.: The role of function in the etiology and treatment of malocelusion, Am. J. ORTHOD. 54: 883-898, 1968. 